\title{
Observisto
}

\section{ESPAÇO, FAMÍLIA E \\ TRABALHO: a publicidade \\ de um país em \\ transformação}

SPACE, FAMILY AND WORK: the advertisement of a country under transformation

\author{
ESPACIO, FAMILIA Y TRABAJO: la \\ publicidad de un país en \\ transformación
}

\section{Bruno Pompeu ${ }^{1,2}$}

\section{RESUMO}

As imensas transformações por que o Brasil vem passando na última década ligadas, como se sabe, ao consumo - têm trazido grandes desafios ao marketing e, consequentemente, à publicidade. Este trabalho pretende discutir, a partir de um olhar interpretativo, como esse novo panorama sociocultural tem se manifestado em termos sígnicos na propaganda brasileira, subvertendo questões básicas, como segmentação demográfica e posicionamento. A partir da perspectiva analítica da semiótica e com os referenciais teóricos da antropologia do consumo, discutimos de

\footnotetext{
1 Publicitário, formado pela Escola de Comunicações e Artes, da Universidade de São Paulo (ECA-USP). É mestre e doutor em Ciências da Comunicação pela Universidade de São Paulo (PPGCOM-USP), tendo se dedicado, nos últimos dez anos, aos estudos do consumo e da comunicação, tendo por base teórico-metodológica a semiótica. É professor do Istituto Europeo di Design (IED-SP) em nível de graduação e pós-graduação, além de ministrar aulas de semiótica, antropologia, comunicação e consumo em nível de pós-graduação em diversas instituições de ensino, como USP, FIA, Senac, Trevisan e Belas Artes. Atua como consultor de pesquisa de mercado em semiótica, tendo já atendido a várias agências de publicidade, institutos de pesquisa e empresas, como Natura, Sadia, Unilever, Nestlé, Record, Josapar, GM, Fiat, Brastemp etc., muitas vezes acompanhando sua orientadora, a Prof. ${ }^{a}$

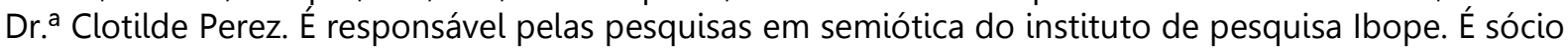
fundador da Casa Semio, espaço dedicado exclusivamente às pesquisas (científicas e de mercado) em semiótica. E-mail: brupompeu@gmail.com.

${ }^{2}$ Endereço de contato do autor (por correio): Istituto Europeo di Design (IED-SP). Rua Maranhão, 617. Higienópolis. CEP: 01240-001. São Paulo (SP), Brasil.
} 


\section{Observatório}

DOI: http://dx.doi.org/10.20873/uft.2447-4266.2016v2Especial2p322

que maneira os imaginários da elite e do popular se manifestam na publicidade brasileira atual, demarcando dois mundos que se completam entre si, entre os quais se transita e a partir dos quais talvez se possa compreender as dinâmicas do consumo contemporâneo.

PALAVRAS-CHAVE: Consumo; marketing; publicidade; segmentação; semiótica.

\section{ABSTRACT}

The immense transformations that Brazil has undergone in the last decade connected, as it is known, to the consumption - have brought great challenges to marketing and advertising. This paper intends to discuss, from an interpretive look, how this new socio-cultural panorama has manifested itself in terms of sign in the Brazilian advertising, subverting basic issues such as demographic segmentation and positioning. From the analytical perspective of semiotics along with the theoretical references of the anthropology of consumption, we examine how the imaginary of the elite and the popular unfold in the current Brazilian advertising, delimiting two worlds that complete one another, between which transitions are allowed and from which maybe we can understand the dynamics of the contemporary consumption.

KEYWORDS: Consumption; marketing; advertising; segmentation; semiotics.

\section{RESUMEN}

Las inmensas transformaciones que Brasil ha experimentado en la última década conectadas, como se sabe, al consumo - han traído grandes desafíos a la comercialización y por lo tanto a la publicidad. En este trabajo se analiza, desde una mirada interpretativa como este nuevo panorama sociocultural se ha manifestado en términos de signos en la publicidad brasileña, subvirtiendo cuestiones básicas tales como la segmentación demográfica y posicionamiento. Desde el punto de vista analítico de la semiótica y con el marco teórico de la antropología del consumo, discutimos de qué manera se manifiestan los imaginarios de la élite y del popular en la publicidad brasileña actual, lo que delimita dos mundos que se completan entre sí, 


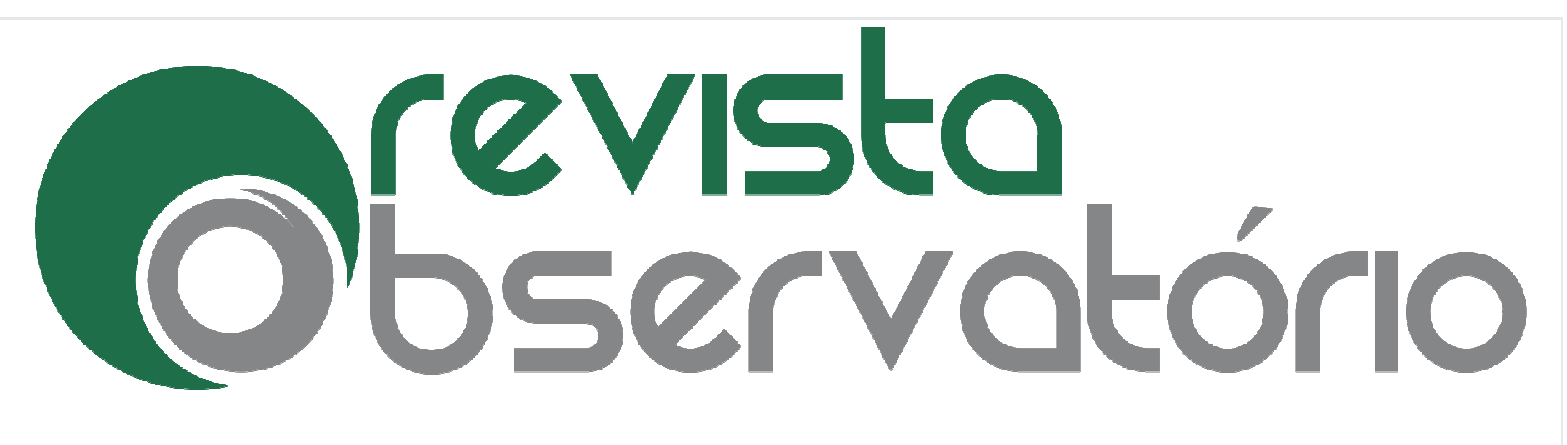

ISSN n² 2447-4266

Vol. 2, Especial 2, outubro. 2016

DOI: http://dx.doi.org/10.20873/uft.2447-4266.2016v2Especial2p322

entre los que se transita y de los cuales tal vez podemos entender la dinámica del consumo contemporáneo.

PALABRAS CLAVE: Consumo; marketing; publicidad; segmentación; semiótica.

Recebido em: 26.07.2016. Aceito em: 19.09.2016. Publicado em: 30.05.2016. 


\section{Observisto}

ISSN n² 2447-4266

Vol. 2, Especial 2, outubro. 2016

DOI: http://dx.doi.org/10.20873/uft.2447-4266.2016v2Especial2p322

\section{Introdução}

Não se pode ser brasileiro e estar de costas para os acontecimentos sociopolíticos que, nos últimos anos, vêm tomando conta das ruas, das redes sociais, das pautas dos veículos de informação e de qualquer ocasião em que se pratique a comunicação. Um crescente sentimento de indignação e revolta tem feito com que milhões de brasileiros sintam vontade de expressar as suas críticas e os seus questionamentos, seja marchando nas ruas, seja compartilhando em seus perfis digitais textos jornalísticos, seja produzindo conteúdos imagéticos.

Também não se pode ignorar, sendo brasileiro, as mudanças socioeconômicas por que a população deste país vem passando nos últimos anos. Gráficos que expressam estatísticas, mostrando a transformação da pirâmide social do Brasil, abundam por toda parte. Sim, dezenas de milhares de pessoas migraram de classe social (NERI, 2011, p. 24) e, mais do que isso, passaram a ter acesso a um universo de consumo até então bastante restrito.

Este texto procura relacionar esse novo e desafiador contexto brasileiro à comunicação publicitária, aos esforços contemporâneos do marketing e ao fenômeno social do consumo. O conteúdo a ser aqui apresentado é desdobramento de uma pesquisa maior, desenvolvida em 2014 em parceria com o instituto de pesquisa Ibope Inteligência, que procurou interpretar essa nova condição conjuntural do país a partir do discurso publicitário das marcas.

Para tal empreitada, foram selecionados diversos veículos de comunicação impressa (basicamente revistas), dos segmentos mais variados, dos quais se extraíram todos os anúncios encontrados. Foram selecionadas revistas destinadas aos públicos mais variados (executivos, jovens, estudantes, mulheres etc.), com conteúdos também diversificados (notícias, fofocas, curiosidades, esportes, estilo de vida etc.), sempre no 


\section{Observisto}

DOI: http://dx.doi.org/10.20873/uft.2447-4266.2016v2Especial2p322

sentido de se encontrar uma variedade de marcas anunciantes e produtos oferecidos que pudesse proporcionar uma maior riqueza o material a ser analisado.

A partir de um referencial teórico multidisciplinar, que aproxima sociologia (questões de classe social), antropologia (consumo como prática simbólica), semiótica (mundo composto por signos) e comunicação (mediatização, publicização, circulação), a pesquisa revelou uma nova possibilidade de mapeamento semântico do consumo brasileiro contemporâneo. Mais do que uma cisão entre classes sociais e marcas destinadas a este ou àquele extrato socioeconômico, o que se viu foi uma publicidade polarizada, bi-refletida nas duas faces de uma mesma moeda.

\section{O Brasil de hoje e os desafios ao marketing}

Tênis que custam cerca de mil reais (o par) e que foram projetados para os pés exigentes e sensíveis dos atletas de alta performance acabaram se transformando em símbolos de uma imensa geração de jovens residentes nas periferias das grandes cidades do Brasil. São jovens que usam os tais tênis não para aumentar a velocidade de suas corridas ou para amortecer impacto de suas pisadas. Justo ao contrário: usam para causar impacto, de preferência quando estão na companhia de seus pares.

Mas outros fenômenos decorrentes - estes, sim, de fato surpreendentes - nos mostram o complexo da situação. Alguns desses jovens passaram a usar esses tênis de uma forma inusitada: um pé de cada cor, para deixar claro a quem os vir que o seu poder de compra vai além dos mil reais. É uma ostentação transgressora, pois subverte a lógica vigente da moda e da estética, propondo um novo padrão de uso e de beleza, que vale menos pela harmonia, pelo equilíbrio ou pelo estilo tradicional do que pelo choque, pelo contraste, pela provocação e pela simples - e legítima vontade de consumir. E, como complexidade pouca é bobagem, já se sabe de jovens, amigos, que calçam o mesmo tamanho de tênis (ou não), indo às lojas de esporte 


\section{Observisto}

DOI: http://dx.doi.org/10.20873/uft.2447-4266.2016v2Especial2p322

dos shoppings, para comprar cada qual o seu par de Nikes e Mizunos e saindo da loja já com os pés trocados.

O fato em si é curioso, chama atenção e não por acaso virou notícia em uma série de reportagens nos últimos anos. Mas seu interesse, para nós, da comunicação, da publicidade e do consumo, está no que ele representa, no fenômeno que ele concretiza em cores tão chamativas. Ao comprarem produtos caros, desenhados para um perfil de público radicalmente distante daquele a que eles pertencem, e ao darem a esses produtos um uso estético que vai além do planejado e do previsto, esses jovens também subvertem e põem em xeque uma lógica de mercado praticada quase sempre unidirecionalmente há décadas, denominada segmentação. E não se trata de condenar esse tipo de consumo - como, inclusive, deve se chegar a pensar nos escritórios executivos -, considerando como errada ou condenável tal prática mercadológica. Compra quem pode pagar, suprem-se determinadas necessidades e o que cabe a nós, pesquisadores, é tomar essas trocas comerciais também como vínculos de sentido e procurar entender o que jaz por trás dessas movimentações inusitadas.

Quando uma equipe de marketing determina que o target de um produto é formado por pessoas de uma determinada classe social, está se definindo que apenas as pessoas incluídas nessa faixa podem ou vão comprar o produto? Claro que não. Não se tem notícia de alguém que, ao procurar um tablete de chocolate, uma cápsula de café expresso ou uma garrafa de água mineral com gás pense antes de escolher por esta ou aquela marca se a sua classe social permite ou limita a sua escolha. Novamente: compra quem pode pagar.

E o que há de novidade no cenário socioeconômico brasileiro é que, de uns anos para cá, muita gente pode pagar por muita coisa. 


\section{Observisto}

ISSN n² 2447-4266

Vol. 2, Especial 2, outubro. 2016

DOI: http://dx.doi.org/10.20873/uft.2447-4266.2016v2Especial2p322

Em 2013, o consumo das famílias cresceu pelo décimo ano seguido. Nesse cenário ainda favorável, a pesquisa do Data Favela atestou que a favela tem mais disposição para efetuar compras do que o resto do Brasil. Nos últimos dez anos, muitas dessas famílias adquiriram o primeiro computador, o primeiro automóvel e o primeiro freezer. Não raro, pela primeira vez, conseguiram matricular um filho em um curso universitário. (MEIRELLES \& ATHAYDE, 2014, p. 87)

Esse novo cenário, portanto, tumultua o até então aparentemente plácido panorama mercadológico brasileiro, pois que permite pessoas de classes sociais distintas - de comportamentos, portanto, também diferenciados, como se acreditou - tendo acesso aos mesmos produtos, às mesmas ofertas, aos mesmos benefícios simbólicos. Mas o mundo contemporâneo já nos mostra há tempos que esse tipo de relação direta, estabelecida entre condição e ação - entre estratificação social e gosto, profissão e comportamento, idade e atitude, por exemplo -, já não faz mais sentido. Em sociedades absolutamente móveis, movediças, transitórias e hipercinéticas, a condição de cada um (sexo, idade, classe social, profissão etc.) determina cada vez menos o seu padrão regular de consumo. De alguns anos para cá, o target

não está mais lá, dócil e imóvel como um animal enjaulado, à espera de que o caçador o alimente ou o acaricie. O corpo do target não pode mais ser caracterizado em termos estatísticos, diversificados nos vários segmentos da estratificação social, visão essa baseada ainda numa produção de valor e de valores do tipo industrialista. Esse target móvel, flutuante, híbrido, solicita novas capacidade de leitura, um olha oblíquo, fluido e sincrético ao mesmo tempo (CANEVACCI, 2007, p. XII).

Everardo Rocha, pesquisador que une comunicação e antropologia, publicidade e consumo, também acha:

o mercado brasileiro da informação exige primeiramente uma compreensão de seu estágio atual e, a partir disso, o desenvolvimento de uma melhor forma para antecipar-se às transformações. Esse quadro se complexifica, 


\section{Observatório}

ISSN n² 2447-4266

Vol. 2, Especial 2, outubro. 2016

DOI: http://dx.doi.org/10.20873/uft.2447-4266.2016v2Especial2p322

sobretudo, ao constatarmos a crescente incorporação de novos contingentes populacionais brasileiros ao universo do consumo, o que torna crucial a investigação, tanto do siginificado cultural de bens e serviços, quanto do valor e do lugar da informação nesse processo. (ROCHA \& PEREIRA, 2013, p. 9)

Detendo-nos apenas na questão das classes sociais, pode-se perceber que o cenário atual é bastante desafiador. Como definir o público-alvo, por exemplo, de um sorvete de palito? Se o mais caro deles (supostamente italiano, sabores sofisticados, embalagem minimalista) custa cerca de dez reais, se o mais barato (assumidamente brasileiro, sabores intensos, embalagem chamativa) não passa de dois, e se entre esses dois extremos há dezenas de outras marcas, cada qual com seu posicionamento, cada qual com seu tipo de produto, cada qual "falando" de um determinado tipo de consumo, onde entram as questões de classes sociais? Não entram, ficam de fora. Já não se consegue mais pensar, para muitas marcas e categorias de produtos, em segmentações desse tipo. Há que se buscar outros critérios, outras formas de direcionar as ofertas.

O que a pesquisa empírica, de mercado, que deu origem a este texto nos ensina é que, pelo menos entre os produtos de consumo diário (comida, bebida, limpeza, higiene etc.) já não existe mais "marca de classe A" ou "marca de classe C" ou pelo menos que esse tipo de pensamento já não ajuda em quase nada.

Duas pessoas, com a mesma pontuação [no Critério Brasil], podem ser muito diferentes no seu padrão de vida, hábitos de consumo, preferências e aspirações, dependendo do local de moradia e grau de instrução. Nesse sentido, fatores ligados ao estilo de vida do entrevistado muitas vezes têm mais peso que a pontuação propriamente dita. (YASUDA \& OLIVEIRA, 2012, p. 266)

O que temos, hoje, é um discurso publicitário que, mais ou menos como acontece na nossa sociedade, se vê dividido, cindido, tensionado, ainda que não se saiba onde está exatamente essa divisão, o que define essa cisão e quais são os polos 


\section{Obsevisto}

DOI: http://dx.doi.org/10.20873/uft.2447-4266.2016v2Especial2p322

dessa tensão. Não se trata de ricos e pobres, como seria fácil pensar, tampouco se pode simplesmente dividir a massa em patrões e empregados, escravos e senhores, brancos e negros, como já se praticou. É ainda um pouco de tudo isso, mas é também muito mais.

Pensar nos contrastes deste país é, muitas vezes, recorrer a Gilberto Freyre. E o que se faz aqui neste texto não é a concordar perfeita com o seu pensamento ou com a totalidade das suas ideias.

O Brasil urbano, industrializado, vivendo em uma situação social na qual as massas estão presentes e são reivindicantes de cidadania e ansiosas por melhores condições de vida, vai continuar lendo Gilberto Freyre. Aprenderá com ele algo do que fomos ou do que ainda somos em parte. Mas não do que queremos ser no futuro. (CARDOSO, 2013, p. 89)

É que no alpendre altivo da casa-grande já não estão mais apenas os brancos, os ricos, os europeus e os proprietários; da mesma forma que no eito simbólico já não se amontoam mais apenas os pretos, os pobres, os nordestinos e os operários. Há muito ainda - e talvez haja de haver para sempre - de Casa-grande \& senzala (FREYRE, 2006) em nossa sociedade, mas cada vez menos o que separa esses dois universos simbólicos vai ser a classe social.

\section{Uma publicidade reveladora do nosso tempo}

$\mathrm{Se}$, conforme comentado acima, não se consegue definir com clareza quais são os critérios que, de fato, servem para demarcar a separação tensionada que se faz evidente em nosso país, devemos nós, os pesquisadores da comunicação, da publicidade e do consumo, verificar como essa realidade se reflete ou se vê culturalmente constituída no discurso publicitário. E o que os procedimentos 


\section{Observatório}

DOI: http://dx.doi.org/10.20873/uft.2447-4266.2016v2Especial2p322

investigativos também já mencionado evidenciaram foi um consumo também baseado em contrastes.

Philip Kotler e Gary Armstrong (2007, p. 22), metonimicamente falando por uma infinidade de autores da área, defendem que o marketing consiste, no fim das contas, em um processo de criação de valor para o cliente. E, neste latifúndio, a parte que cabe à comunicação publicitária é a tarefa de contribuir para a construção desses significados (valores). Marketing e comunicação acabam, então, concordando no que se refere ao fato de que os atos de consumo podem ser divididos em racionais e emocionais (KOTLER \& ARMSTRONG, 2007, p. 363; YANAZE, 2011, p. 436). A emoção sustenta aquele consumo mais sensorial, mais subjetivo, mais vinculado ao sentir, muitas vezes com apelos que se distanciam da oferta concreta do produto; enquanto a razão dá base para o consumo mais funcional, mais objetivo, mais centrado na solução de uma necessidade, ligado à praticidade e à conveniência.

Sabe-se também que, especialmente no contexto brasileiro, de acordo com o pensamento antropológico de Roberto DaMatta, nossos rituais podem ser divididos simbolicamente entre os que ocupam o espaço simbólico da casa (o doméstico, o íntimo, o familiar, o próximo) e o da rua (o urbano, o coletivo, o social, o distante).

Quando digo que "casa" e "rua" são categorias sociológicas para os brasileiros, estou afirmando que, entre nós, estas palavras não designam simplesmente espaços geográficos ou coisas físicas comensuráveis, mas acima de tudo entidades morais, esferas de ação social, províncias éticas dotadas de positividade, domínios culturais institucionalizados. (DAMATTA, 1997, p. 15)

O cruzamento dessas duas divisões (consumo racional vs. consumo emocional e consumo individual vs. consumo coletivo) ainda não representa - nem se pode assim pretender - o contraste a que se referiu acima. Apenas estabelece um mapa geral do consumo brasileiro, plasmado signicamente no discurso publicitário das 


\section{Observatório}

DOI: http://dx.doi.org/10.20873/uft.2447-4266.2016v2Especial2p322

marcas anunciantes, demarcado em quatro quadrantes: (1) emocional-rua: diferenciação social, mostrar ao outro quem eu sou, gerar pertencimento e favorecer autoexpressão; (2) racional-rua: impacto social dos atos, consumir pensando no coletivo, sentido de pátria e produtividade; (3) racional-casa: satisfação de necessidades, resolver problemas práticos, aumento do conforto e vínculo com a comunidade; (4) emocional-casa: satisfação de desejos, ter prazer e sentir-se bem, espaço da família e das indulgências.

O contraste propriamente dito (político, econômico, ideológico, social, cultural etc.), esse que se sente nas ruas, que se lê nos livros e que se comenta a todo instante, se fez evidente através das análises semióticas das peças publicitárias selecionadas. Se "em cada anúncio vendem-se, significativamente, mais estilos de vida, visões de mundo, sensações, emoções, relações humanas, sistemas de classificação do que os bens de consumo efetivamente anunciados" (ROCHA, 2006, p. 16) - nunca esquecendo que, atualmente, o acesso à dimensão concreta desses anúncios, os ditos bens, já se faz mais generalizada -, e se "a publicidade e o comportamento do consumidor refletem esses significados" (SANTAELLA \& NÖTH, 2010, p. 50), o que se está praticando aqui é uma interpretação desse contexto conturbado do país por meio do discurso publicitário das marcas. Os universos sígnicos construídos na publicidade, a seleção de cores, formas, enquadramentos, imagens, tipografias, todas as opções semânticas, o tipo de texto e de argumento utilizados, tudo isso (e muito mais, iconicidades, indicialidades e simbolicidades) foi analisado pelo método semiótico de Charles Peirce (SANTAELLA, 2004a, 2004b, 2004c) e o que se viu foi uma constante separação, uma recorrente divisão, uma demarcação clara de dois mundos simbólicos culturalmente divergentes. A seguir, alguns exemplos procuram evidenciar que mundos são esses. 


\section{Observisto}

ISSN n² 2447-4266

Vol. 2, Especial 2, outubro. 2016

DOI: http://dx.doi.org/10.20873/uft.2447-4266.2016v2Especial2p322

\section{Espaço de referência: o camarote e a comunidade}

Em diversos anúncios analisados, emergiram duas instâncias espaciais distintas, não opostas entre si, talvez até certo ponto complementares, mas nitidamente diferentes em termos semânticos.

Constituído culturalmente como um espaço desejado e privilegiado, o camarote se destaca - não apenas nos anúncios relacionados com festas, shows e eventos de entretenimento, mas em uma série da categorias de produtos. Ou seja: não se está falando literalmente do acesso aos camarotes reais, está se fazendo menção a um espaço simbólico culturalmente desejado, de onde se pode ser visto pela multidão, mas que dificilmente é invadido. É do camarote que se aproveita o melhor da festa, o melhor da vida. É uma forma de se estar com o todo, com todos, participar do que de mais mundano, prazeroso e divertido a vida pode oferecer, mas em um patamar demarcado pela restrição e pela exclusividade.

Nunca se valorizou tanto a exclusividade, essa exclusividade exposta, de se estar aqui, com poucos, protegidos e bem servidos, mas podendo desfrutar das mesmas coisas que estão aí, ao alcance de todos. Essa exclusividade está explícita no conceito do camarote, é claro, mas está também nas áreas VIP, nas varandas (gourmet), nos clubes e nas confrarias, no gold, no platinum e no titanium dos cartões de crédito, no prime, no select e no personalité dos bancos. Ela se revela signicamente numa demarcação territorial evidente, que pode se dar de várias maneiras, mas sempre demonstrando haver dois espaços distintos: um que é o daqui, atrás do anteparo, ligeiramente acima, ao mesmo tempo aberto e protegido, exposto e aconchegante; outro é o daí, próximo, cuja vibração e intensidade se sente de perto, onde estão os quase iguais a mim. 


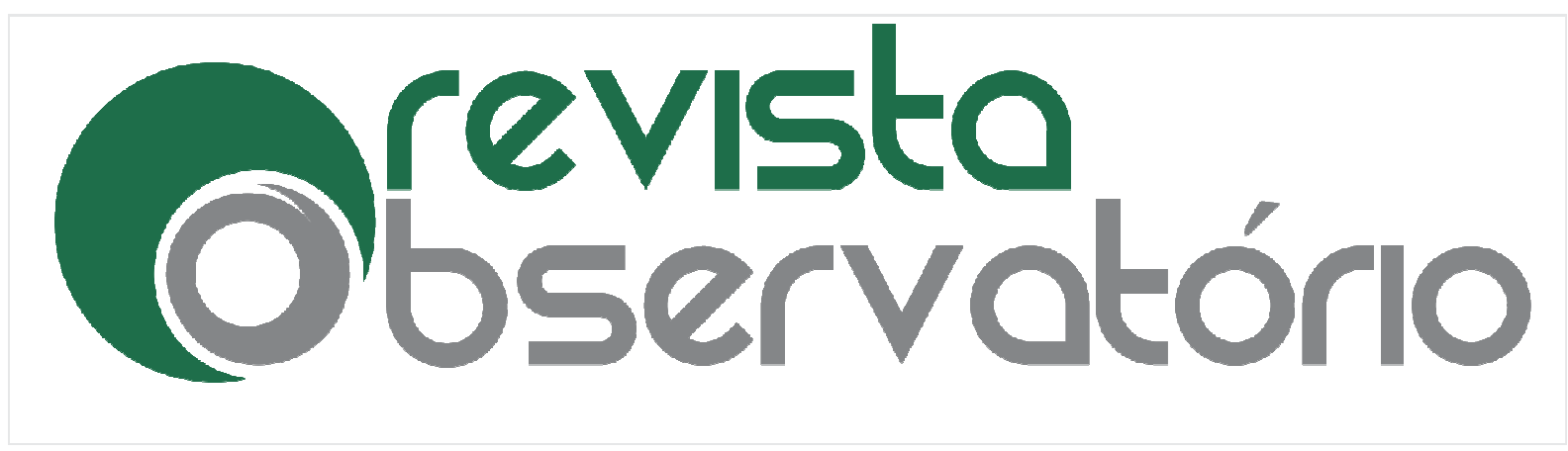

ISSN n² $2447-4266$

Vol. 2, Especial 2, outubro. 2016

DOI: http://dx.doi.org/10.20873/uft.2447-4266.2016v2Especial2p322

Essa demarcação territorial pode estar expressa em uma paleta de cores mais sóbria e restrita. A policromia festiva é da massa, é de todos, é do Romero Britto e da multidão. O camarote tem cores bem selecionadas, é sépia, preto e branco, monocromático. Pode-se ser também mais explícito e assumir realmente o ponto de vista da varanda ou do balcão. Daqui, vê-se tudo, curte-se tudo, acessa-se qualquer coisa, mas nada me atinge, nenhuma mazela me afeta. No camarote há menos pessoas, a ele ascendem somente alguns - que não os ricos, fique claro, mas sim os que têm o nome na lista ou o acesso à pulseirinha.

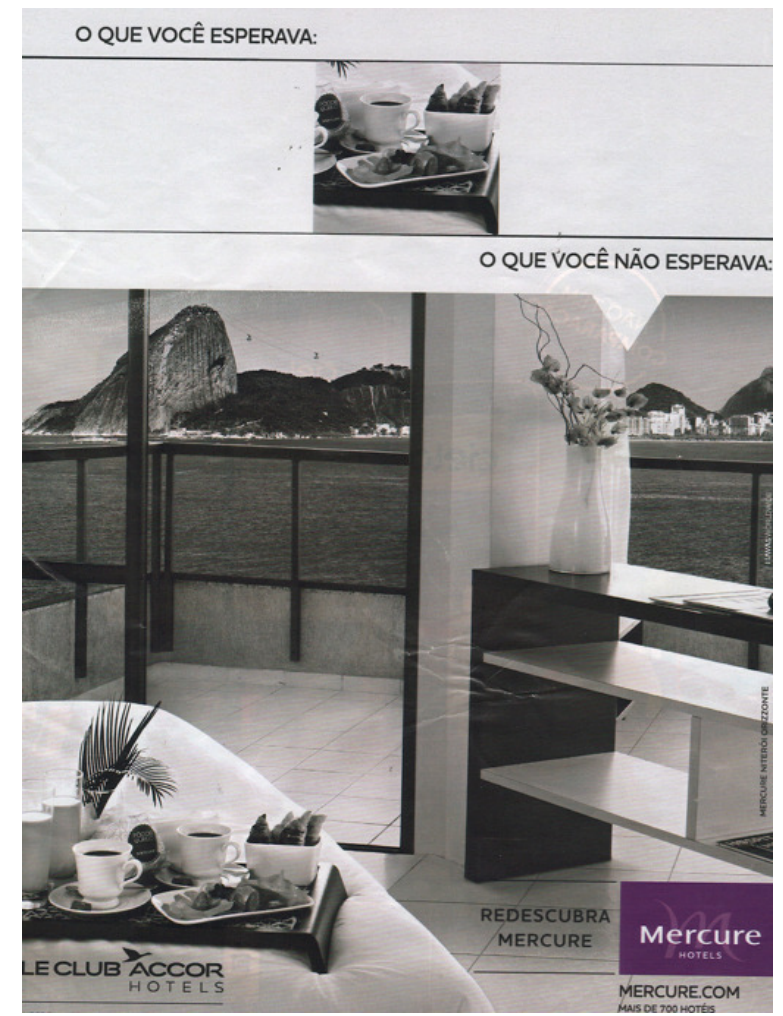

Figura 1: Anúncio do Hotel Mercure, espaço protegido do balcão. 


\section{Observatório}

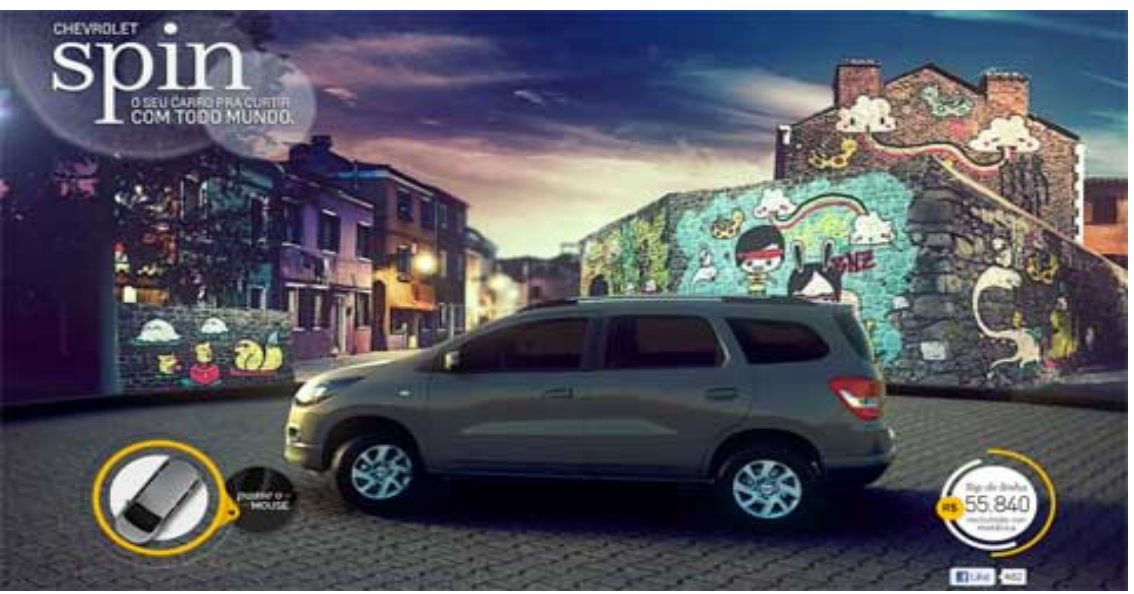

Figura 2: Anúncio do carro Chevrolet Spin, o espaço grafitado do beco.

O anúncio de cima - de uma rede de hotéis - revela duplamente a estética e o universo simbólico do camarote. Não só as cores variadas são deixadas de fora, como se apresenta o serviço oferecido (hotel, hospedagem) a partir de um ponto de vista de resguardo, mas de onde se pode aproveitar o que a vida oferece. $\mathrm{Na}$ imagem, ninguém. Ou seja: o consumo do camarote é aquele que oferece o que está ao alcance de todos (serviços bancários, turismo, diversão, moradia etc.), mas com certo sentido de exclusividade. Não são produtos diferentes, são espaços diferenciados.

Destaca-se, também, ainda na esfera das demarcações espaciais simbólicas, a comunidade. É o espaço da favela, da periferia, da quebrada, do bairro pobre e, de certa forma, do gueto. É o Divino, é a Babilônia, é Paraisópolis, é ZL, Vidigal e Madureira. Aqui, o ninguém não existe. É sempre muita gente e o vínculo coletivo se expressa em sentidos de cooperação, convivência e compartilhamento de dificuldades e alegrias.

Novamente: não se está falando aqui de produtos para pobres, periféricos ou favelados. O que se está procurando demonstrar é que, no mundo constituído pela propaganda, independente da classe social de que se esteja falando, a comunidade 


\section{Observatório}

ISSN n² 2447-4266

Vol. 2, Especial 2, outubro. 2016

DOI: http://dx.doi.org/10.20873/uft.2447-4266.2016v2Especial2p322

se revela um espaço também desejado, só que não pela exclusividade, mas pela sua capacidade de ser criativa, espontânea, efervescente, autêntica, permissiva e transgressora. São da comunidade o funk, o rap, o samba e o hip-hop, assim como também o são o passinho, o charm, a Anitta e o batidão.

O anúncio de baixo - de uma marca de veículos - mostra uma das formas mais recorrentes de se representar signicamente esse espaço. Texturas mais brutas (do zinco, do bloco e do asfalto) contrastam com um imenso e impactante colorido (do grafite, da natureza teimosa, do mosaico social e das roupas comuns dependuradas), sugerindo que, na comunidade, ao contrário do que acontece no camarote, está a massa, estão todos. Se o que se oferece na campanha é massivo, popular, novo, miscigenado, transgressor, urbano, atual, provocante e pulsante, 0 espaço dele é a comunidade.

\section{Família: a rotina e a tradição}

O universo familiar não é apenas um vastíssimo campo para o consumo concreto (produtos para a casa, por exemplo), como é também um poderoso componente simbólico de muitos anúncios. Usar a família como argumento de vendas, como conteúdo publicitário ou como elemento estético sempre foi empreendimento comum na propaganda brasileira. $\mathrm{O}$ que a pesquisa em questão revelou, entretanto, foram dois caminhos diferentes de abordagem dessa família. De um lado, a família de todo dia, do outro, a família tradicional. Vejamos: 


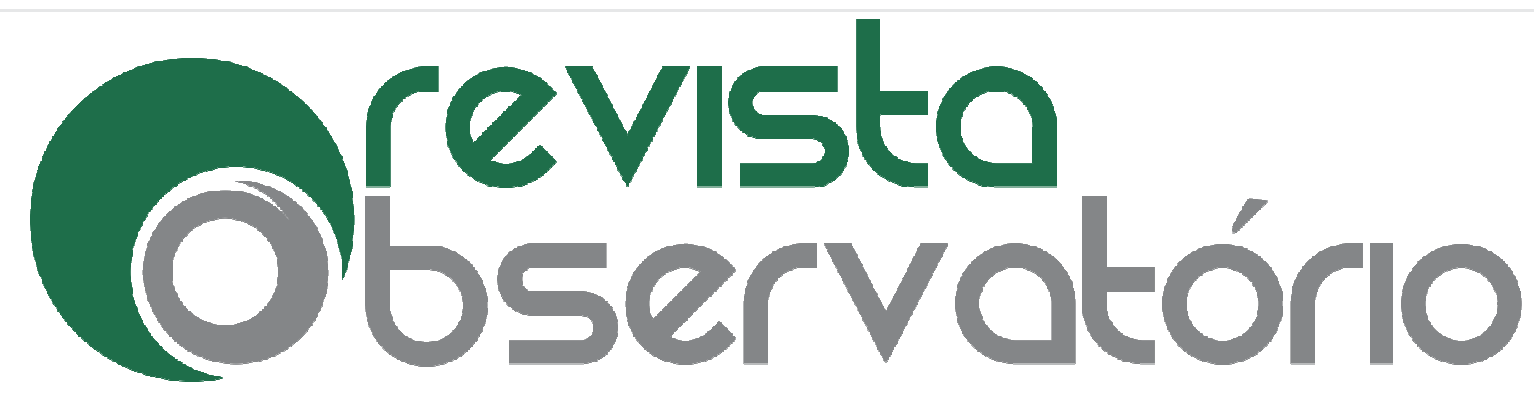

ISSN n² 2447-4266

Vol. 2, Especial 2, outubro. 2016

DOI: http://dx.doi.org/10.20873/uft.2447-4266.2016v2Especial2p322

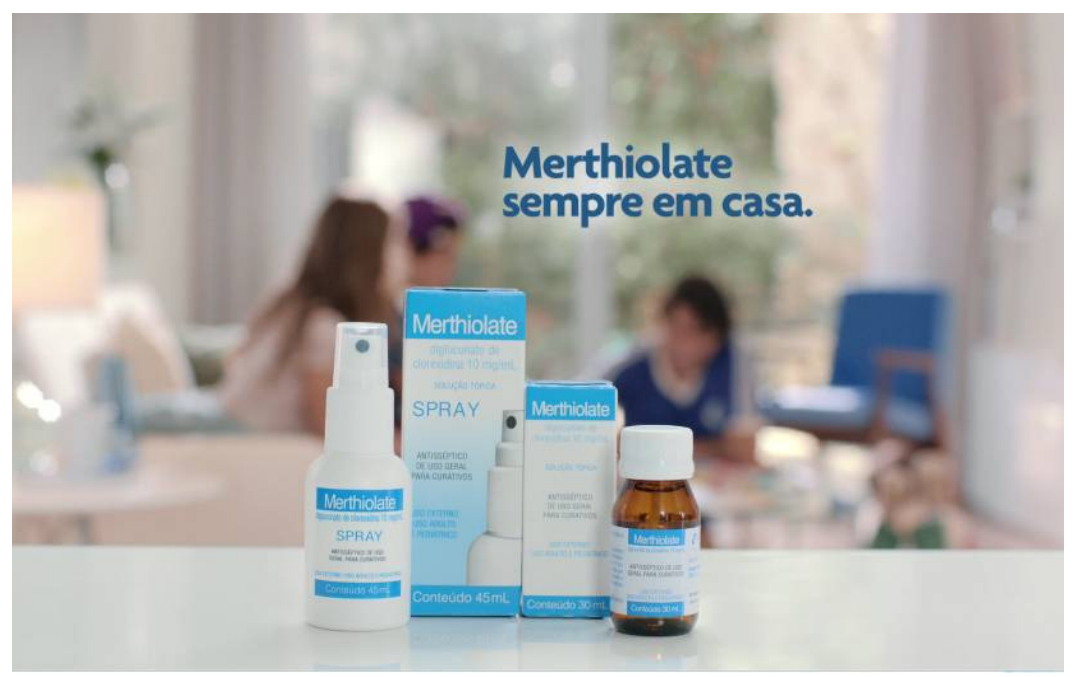

Figura 3: Anúncio do remédio Merthiolate, a família da rotina.

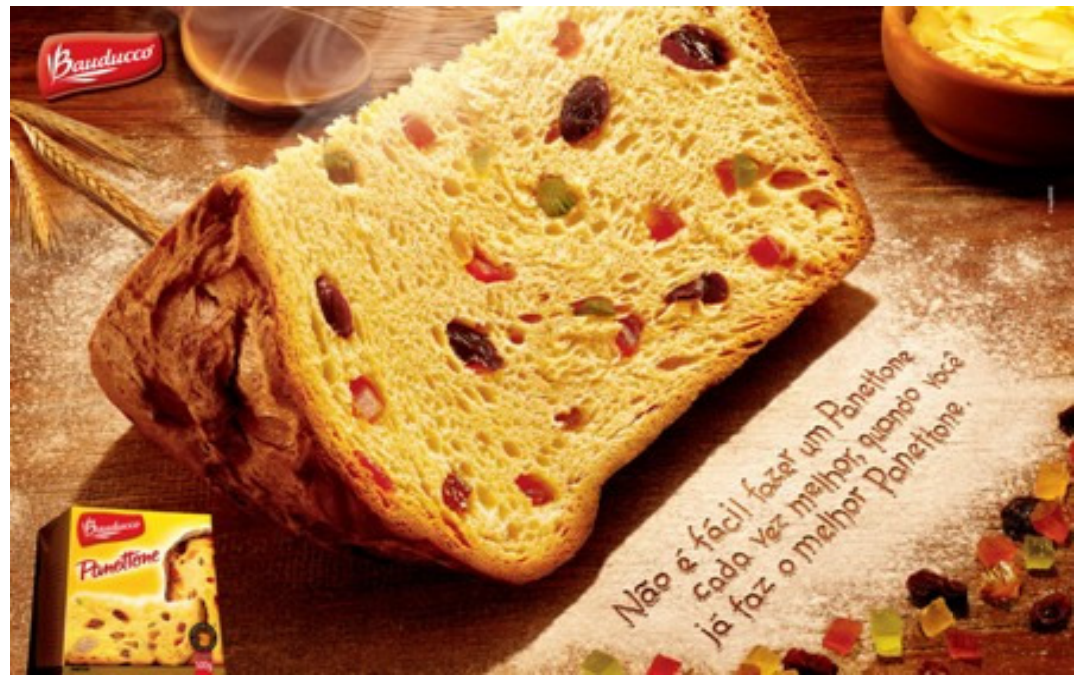

Figura 4: Anúncio do panetone Bauducco, a família da tradição.

O que o anúncio de cima - de uma famosa marca de remédio para machucados - expressa são vínculos familiares que se reforçam no dia-a-dia, na rotina, no cotidiano de cada casa. É a família do agora, do hoje, do nome próprio, do almoço e do rame-rame diários - dos arranhões, dos acidentes e dos acontecimentos prosaicos. Já no anúncio de baixo - de uma marca especializada em panetones, colombas e biscoitos -, a família parece incorporar sentidos diferentes, não tão 


\section{Observatório}

DOI: http://dx.doi.org/10.20873/uft.2447-4266.2016v2Especial2p322

presentistas, mas mais alongados no tempo. É a família de ontem, do passado (ancestralidade, herança) e a família de amanhã, do futuro (legado, dinastia) - das receitas, dos segredos, do sobrenome e dos elementos poéticos. Não por acaso, as cores de uma dessas famílias são claras, ensolaradas, plasmadas em superfícies plásticas, em enquadramentos mais amplos e coletivos, enquanto a outra se manifesta em cores escuras, quentes, amparadas em superfícies de madeira, com muitos closes e perspectivas intimistas.

Mas não se trata de dividir a família representada na publicidade brasileira entre famílias de ricos ou famílias de pobre - afinal, quanto custa um pote de margarina? Trata-se de perceber que essa instituição cultural, no nosso contexto atual, recebe dois tratamentos distintos, cada qual expressando sentidos diferentes: ambos alicerçados nos papéis bem definidos (pai, mãe, filhos, avós...), na hierarquização sanguínea, como ensina Roberto DaMatta (1997), mas um caminho mais conectado com valores de rotina e outro mais próximo do conceito de tradição.

\section{Trabalho: o estratégico e o operacional}

Dentro do quadrante racional-rua, destaca-se o consumo que de alguma forma se relaciona com o trabalho, seja nas categorias voltadas a esse universo (uniformes, utensílios, tecnologia etc.), seja por meio de conexões simbólicas (produtividade, excelência, conquista etc.). E, hoje em dia, quando se analisam os sentidos culturais incutidos nas publicidades que de alguma forma tangenciam o universo do trabalho, também é possível identificar dois caminhos bastante diferentes entre si - ainda que diretamente relacionados.

Pode-se estar falando de um trabalho mais ligado ao pensamento, ao planejamento, à tomada de decisões e à autoridade. É o trabalho dos que mandam, dos chefes e dos executivos, dos que ocupam cargos mais elevados, da camisa azul do gerente, da cadeira preta do diretor. Mas pode-se também falar de um outro tipo 


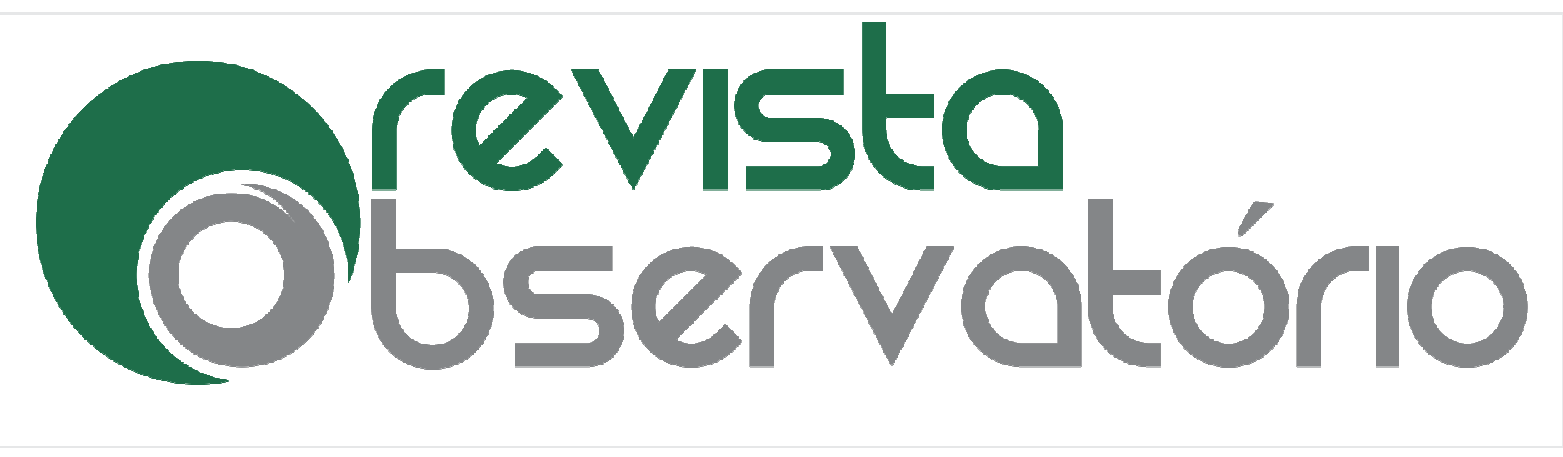

DOI: http://dx.doi.org/10.20873/uft.2447-4266.2016v2Especial2p322

de trabalho, mais próximo da execução, da operação, da realização concreta. É o trabalho dos que obedecem, dos empregados, dos funcionários e dos colaboradores, do uniforme, do crachá e das mesas padronizadas.

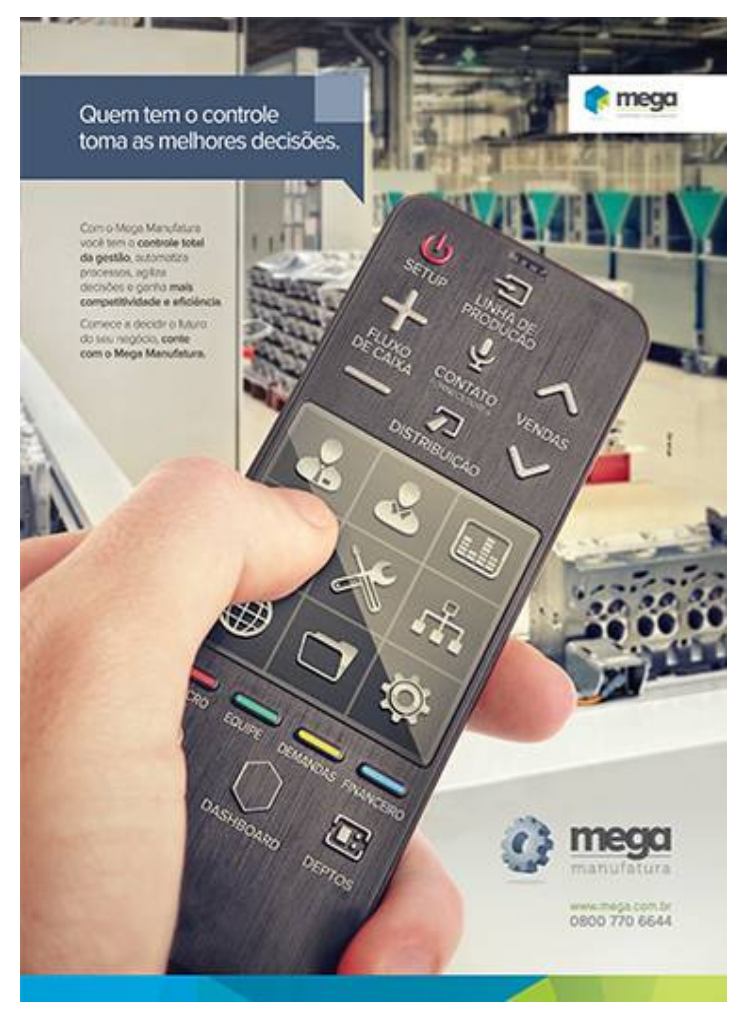

Figura 5: Anúncio da Mega Manufatura, a dimensão estratégica do trabalho. 


\section{Observisto}

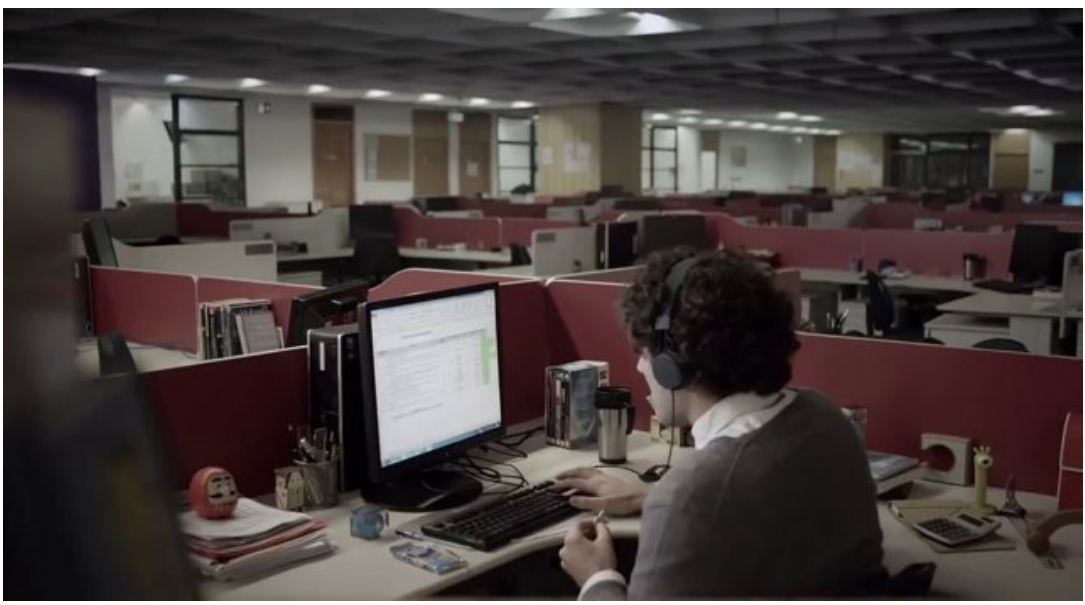

Figura 6: Anúncio do biscoito Club Social, a dimensão operacional do trabalho.

Simbolicamente, o que esses dois tipos de trabalho vão sinalizar são dois grupos de valores também bastantes distintos. O trabalho estratégico (o dos que decidem, exemplificado com o anúncio de cima, de uma empresa de tecnologia de gestão empresarial) sugere sentidos de excelência, alta performance, autonomia, controle e reconhecimento pela autoridade; ao passo que o trabalho operacional (o dos que executam, como se verifica na peça de baixo, de uma famosa marca de biscoitos) suscita sentidos de esforço, ralação, superação, dedicação e reconhecimento pelo bom desempenho.

Mais uma vez é preciso que se diga que, ainda que se encontrem relações mais claras entre essa divisão simbólica do trabalho e outras formas de classificação (como as da sociologia, de base marxista ou weberiana, ou como as já citadas perspectivas gilbertianas), o mais importante, no escopo deste estudo, é entender nem sempre o universo do trabalho vai ser usado por produtos diretamente relacionados com esse âmbito. E o trabalho, como valor simbólico, acaba assumindo essas duas perspectivas destacadas, uma mais elitizada, nem por isso voltada necessariamente a pessoas mais ricas ou a categorias de produtos mais caros; e outra 


\section{Observisto}

ISSN n² 2447-4266

Vol. 2, Especial 2, outubro. 2016

DOI: http://dx.doi.org/10.20873/uft.2447-4266.2016v2Especial2p322

mais popular, sem que obrigatoriamente seja destinada a pessoas de menor poder aquisitivo.

\section{Considerações finais}

Elitizado e popular. As palavras usadas no parágrafo acima talvez sejam as mais adequadas para classificar os dois distintos e tensionados universos simbólicos em que se divide atualmente o consumo brasileiro, expresso por meio da sua publicidade. Não se trata de um consumo de rico, de classe A, ou de pobre, de classe C, D ou E. Trata-se de um consumo motivado por valores e construído culturalmente com sentidos. Ou seja: trata-se de uma abordagem do consumo a partir da perspectiva do significado, daí a junção teórica da comunicação (publicitária), da antropologia (do consumo) e da semiótica (peirceana).

Em um tempo em que, como já se sabe, as estratificações demográficas dentre as quais a socioeconômica - determinam menos os padrões de consumo do que outras variáveis menos mensuráveis, os desafios a quem deseja classificar a sociedade em grupos são imensos. Ainda que novos modelos de estratificação socioeconômica venham sendo elaborados e demonstrem certa eficiência em sua capacidade de agrupar a população a partir de critérios bem definidos e bem quantificáveis (KAMAMURA \& MAZZON, 2013), cumpre que se considerem outras esferas de classificação. Esferas que eventualmente atravessam as classes sociais, revelando vínculos de sentido - de consumo - entre marcas e pessoas, independente dos critérios de segmentação de sempre. Não é abandonar uma das possibilidades ou optar por outra isoladamente: é entender que, dentro de um determinado estrato socioeconômico, por menos que se queira ou se acredite, existe um comportamento indomável e irrequieto do consumidor, que responde, claro, não apenas à sua faixa de renda, à quantidade de banheiros na sua casa ou ao seu nível de escolaridade, mas também aos seus anseios simbólicos mais relevantes e imprevisíveis. 


\section{Observisto}

ISSN n² 2447-4266

Vol. 2, Especial 2, outubro. 2016

DOI: http://dx.doi.org/10.20873/uft.2447-4266.2016v2Especial2p322

O que este texto propõe é uma outra forma de se classificar a sociedade brasileira quando se pensa em consumo. Se o fim do target se anuncia (PEREZ, 2009), para que mirar na mosca, se a mosca não cessa de voar e voa mais rápido do que as raquetes eletrificadas do marketing conseguem supor? Em vez de mirarmos na pessoa, parada e dócil, como diz Canevacci, miramos em um determinado território simbólico. Quanto mais acurada for a nossa capacidade - dos publicitários, dos marqueteiros, dos designers - de compreender essa dimensão simbólica e transferir seus significados para produtos, marcas e campanhas publicitárias, maior será a chance de atingirmos as pessoas. Porque elas, pessoas consumidoras, estão constantemente em movimento, transitando entre este e aquele território, ora consumindo o camarote, ora preferindo a comunidade - mas quase sempre com um pé cá e outro lá.

O que as análises dos materiais publicitários selecionados revelou foi também um princípio de generalizações entre o universo do consumo elitizado e o universo do consumo popular. É evidente que nuanças relevantes existem entre essas duas dimensões, mas de uma forma geral é possível apontar diferenças. O universo simbólico do consumo de elite, por exemplo, lida com o tempo alongado, com o passado e com o futuro, tem um vetor apontado para o qualitativo (melhorar, especificar, detalhar), apresenta uma relação de proximidade entre os que podem estar longe (física e simbolicamente), sugere estilo e sofisticação. É o camarote, o cobranding, a excelência, o mundo globalizado, o gourmet, o premium, o deleite, a exclusividade e a sofisticação.

Já o universo simbólico do consumo popular, por outro lado, está ligado diretamente com o tempo do agora, com o presente e com a rotina, tem seu vetor apontado para o quantitativo (aumentar, majorar, ampliar), evidencia uma relação estreita com os que estão necessariamente próximos (física e contingencialmente), 


\section{Observatório}

DOI: http://dx.doi.org/10.20873/uft.2447-4266.2016v2Especial2p322

sugere mistura e experimentação. É a comunidade, o esforço, o acesso, a brasilidade, a mistura, o inaugural, o massivo, o rotineiro e o festivo.

E O mais importante: nenhum desses universos está obrigatoriamente amarrado a nenhuma classe social.

Quando a opinião pública se materializa na nossa frente, na nossa rua, ao nosso redor, impondo a toda e qualquer pessoa o contato com uma realidade social conturbada, tensionada, conflituosa, desafiadora e incompreensível, o melhor a se fazer é pensar. "Está claro que não vivemos no melhor mundo possível. Os protestos globais devem servir de lembrança ao fato de que temos a obrigação de pensar em alternativas" (ZIZEK, 2013, p. 108).

As palavras do pensador são inspiradoras e ao mesmo tempo nos enchem de responsabilidade. Pensar a publicidade e o consumo, hoje, diante do que temos como panorama social no Brasil, é buscar novas formas de enxergar as relações entre pessoas e marcas.

\section{Referências}

DAMATTA, Roberto. A casa \& a rua: espaço, cidadania, mulher e morte no Brasil. 5. ed. Rio de Janeiro: Rocco, 1997.

CANEVACCI, Massimo. Publicidade transitiva: para minorias não-minoritárias. In: PEREZ, Clotilde; BARBOSA, Ivan Santo. Hiperpublicidade 1: fundamentos e interfaces. São Paulo: Thomson Learning, 2007.

CARDOSO, Fernando Henrique. Pensadores que inventaram o Brasil. São Paulo: Companhia das Letras, 2013.

FREYRE, Gilberto. Casa-grande \& senzala: formação de famílias brasileiras dob o regime da economia patriarcal. 51. ed. São Paulo: Global, 2006. 


\section{Observisto}

KAMAKURA, Wagner A.; MAZZON, José Afonso. Estratificação socioeconômica e consumo no Brasil. São Paulo: Blucher, 2013.

KOTLER, Philip; ARMSTRONG, Gary. Princípios de marketing. 12. ed. São Paulo: Pearson Prentice Hall, 2007.

MEIRELLES, Renato; ATHAYDE, Celso. Um país chamado favela: a maior pesquisa já feita sobre a favela brasileira. São Paulo: Gente, 2014.

NERI, Marcelo. A nova classe média: o lado brilhante da base da pirâmide. São Paulo: Saraiva, 2011.

ROCHA, Everardo; PEREIRA, Cláudia (orgs.). Cultura e imaginação publicitária. Rio de Janeiro: Mauad, 2013.

ROCHA, Everardo. Representações do consumo: estudos sobre a narrativa publicitária. Rio de Janeiro: Mauad, 2006.

SANTAELLA, Lucia. O método anticartesiano de C. S. Peirce. São Paulo: UNESP, 2004a.

A teoria geral dos signos: como as linguagens significam as coisas. São Paulo: Pioneira Thomson, 2004b.

Semiótica aplicada. São Paulo: Pioneira Thomson Learning, 2004c.

SANTAELLA, Lucia; NÖTH, Winfred. Estratégias semióticas da publicidade. São Paulo: Cengage Learning, 2010.

YANAZE, Mitsuru Higuch. Gestão de marketing e comunicação: avanços e aplicações. 2. ed. São Paulo: Saraiva, 2011. 


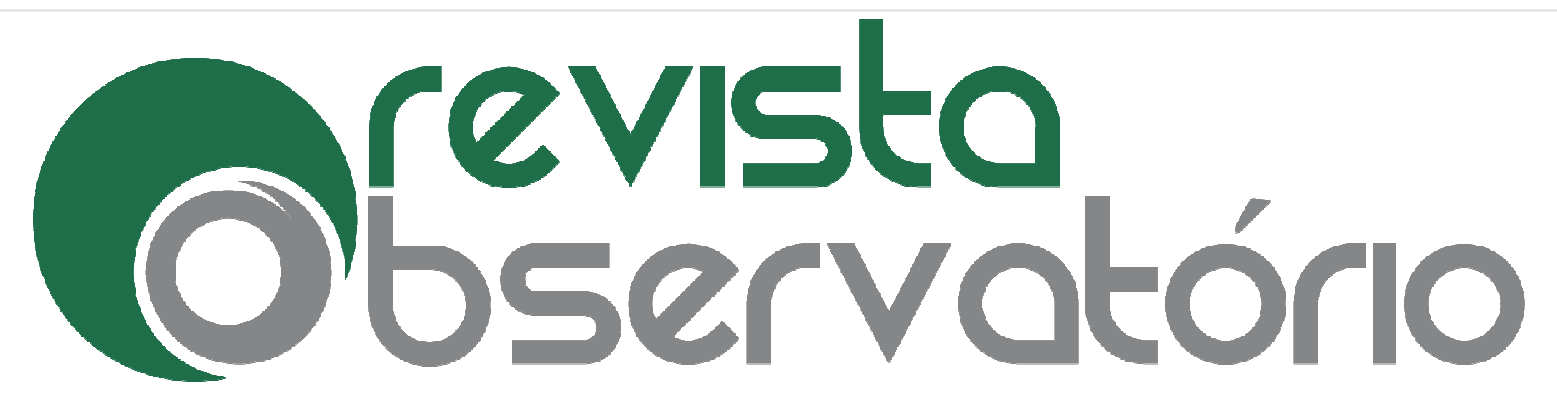

ISSN n² 2447-4266

Vol. 2, Especial 2, outubro. 2016

DOI: http://dx.doi.org/10.20873/uft.2447-4266.2016v2Especial2p322

YASUDA, Aurora; Oliveira, Diva Maria Tammaro de. Pesquisa de marketing: guia para a prática de pesquisa de mercado. São Paulo: Cengage Learning, 2012.

ZIZEK, Slavoj. Problemas no paraíso. In: Cidades rebeldes: Passe Livre e as manifestações que tomaram as ruas do Brasil. São Paulo: Boitempo, 2013. 